\title{
Fuzzy Logic Model to Support Risk Assessment in Innovation Ecosystems
}

\author{
António Abreu \\ Mechanical Engineering Department \\ ISEL - Inst. Sup. de Engenharia de \\ Lisboa / CTS - Uninova \\ Lisboa, Portugal \\ ajfa@dem.isel.ipl.pt
}

\author{
José Duarte Moleiro Martins \\ ISCAL - Inst. Sup. de Cont. e \\ Administração de Lisboa \\ UNIDE - ISCTE - IUL \\ Lisboa, Portugal \\ zdmmartins@gmail.com
}

\author{
J. M. F. Calado \\ Mechanical Engineering Department \\ ISEL - Inst. Sup. de Engenharia de \\ Lisboa / IDMEC-LAETA-IST-UL \\ Lisboa, Portugal \\ jcalado@dem.isel.ipl.pt
}

\begin{abstract}
Nowadays, enterprises in global markets must achieve high levels of performance and competitiveness to stay "alive". According to several authors and as frequently mentioned by reports of practical case studies, one of the most relevant sources of competitive advantage is the innovation capacity. The identification and quantification of the existing or potential innovation risks in a collaborative environment, is an important element for the wide adoption of the innovation ecosystem paradigm. However, models to understand the innovation risks in a collaborative environment are lacking. To address this issue, this paper introduces an approach based on a qualitative assessment, including a quantitative basis, whose development was supported by fuzzy logic for analyzing the level of risk in co-innovation projects. Finally, based on experimental results from a Portuguese collaborative network, a discussion about the benefits and challenges found are discussed.
\end{abstract}

Keywords - risk analysis; fuzzy logic; style; fuzzy reasoning; innovation; collaborative ecosystems.

\section{INTRODUCTION}

Innovation is the main source of economic growth and new employment opportunities, providing potential benefits to society and the economy. In the face of competition from lowwage economies - such as China - the Western economies can only compete and survive through innovation, that is, the discovery of new and better products and operational processes [1].

According to Afuah [2], innovation includes applying new knowledge to provide a new product or service desired by customers. Innovation refers to the economic application of a new idea. Process innovation involves a new or changed way of producing a product. Product innovation implies a new or altered product.

Innovations vary in nature, scale or degree of novelty. This implies that companies take risks associated with the development and launch of new products, quickly and successfully in the market. Thus, the ability to identify and control risk is considered of vital importance in innovative enterprises [3]. Companies to survive, must innovate at a pace unparalleled earlier, and in a larger context of uncertainty in the market. This means that the risk level of companies is increasing [4]. According to 31000 ISO standard defines risk as the effect of uncertainty on objectives [5]. Any factor that affects the performance of a project can be a source of risk. The risk arises when this effect has an uncertain and significant impact on project performance [6].
In order to mitigate the risks associated with innovation, companies enter into collaborative agreements because they do not have all the necessary resources, including knowledge [7]. That is, there is a premise that the existence of a 'healthy' collaborative environment allows companies to operate more efficiently on cost / time / quality in the development of innovation processes and thereby be more competitive. Innovation network members "divide the value chain of innovation" into a variety of tasks where the assignment of these tasks to each partner is based on identifying the resources that have the lowest costs and the best skills and / or access to specific knowledge in order to maximize gains $[8,9]$.

However, it is reported by most small and medium-sized enterprises (SMEs) managers that the development of innovation processes in the context of a collaborative environment introduces additional risks. Do the potential benefits outweigh the additional risks? The publications on this subject seem to indicate that the answer is yes. However, it is still difficult to prove $[10,11]$. The absence of management tools that are robust enough to detect and even anticipate potential risks associated with the development of an innovation project in a collaborative context is an obstacle to the proliferation of this way of working. According to several authors [12, 13], there are currently a number of tools that can be used to identify and analyze the risk where the most used are: Decision Trees, Brainstorming, Structured or Semi-Structured Interviews, Delphy's Analysis, Risk Matrix, Cause-Effect Diagrams, Failure Modes and Effects Analysis (FMEA), Bayes Networks, among others.

In this paper, it will be discussed the advantages of applying fuzzy logic in the evaluation of risks with negative impact, that is, events of potential threat to the success of an innovation project in a collaborative context. Thus, section II describes the types of risks in the processes of co-innovation. Section III describes the proposed model of innovation risk assessment in collaborative ecosystems. The robustness of the proposed approach is evaluated in Section IV considering a case study. And, finally, Section $\mathrm{V}$ provides some concluding remarks.

\section{TYPES OF RISKS IN THE PROCESSES OF CO- INNOVATION}

Most of the work done on the identification and characterization of innovation risks does not follow a standardized approach and the use of ad hoc approaches may lead to some relevant risks being difficult to identify $[14,15]$. As Fig. 1 illustrates, for the identification of risks associated with 
innovation processes in a collaborative context, the following dimensions were defined: pure risk or uncertainty, risk of an innovation project and the collaborative risk.

Pure risk or uncertainty - This dimension of risk is related to the probability of an event occurring that endangers the success of the innovation project.

Risk of an Innovation Project - This dimension of risk is related to the fact that a project is a unique effort and there is a substantial portion of the risks associated with estimates, such as: resources, duration of the task, costs, among others. In this dimension of risk, it is possible to define three classes of risks or vulnerabilities:

- Business risk - Risk related to the loss of a business opportunity. The identification and characterization of this type of risk includes the following aspects: commercial viability, commercialization capacity, customer responsiveness and response, competitors, among others.

- Political risk or regulation - Risk related to decision making in a favorable political context described in the literature as a Blue Ocean Strategy (BOS), as opposed to the conventional market characterized by a high level of competition characterized as a Red Ocean Strategy (ROS)) [16].

- Operational risk - Risks related to the ability to perform tasks or/and operations without errors. The identification and characterization of this type of risk comprises the following aspects: who performs a task for the first time or performs a complex task and is able to do so? How many tasks cannot be performed if a resource is removed? Entities have access to the resources needed to perform tasks such as: the supply chain, information, technology, suitable skills, among others.

Collaborative Risk - This dimension of risk is related to the fact that a collaborative ecosystem can be characterized by a set of relationships that are established between several entities, such as companies/organizations, knowledge, resources and tasks. In this dimension, it is possible to define four classes of risks or vulnerabilities resulting from the interaction between the entities that are members of the ecosystem:

- Risk of critical enterprises - Risks associated with network members who have exclusive competencies, resources or are assigned to a task of great complexity. The identification and characterization of this type of risk comprises the following aspects: Does the removal of a partner affect the ability to achieve the defined objectives? Are there companies that have access to unique skills, resources or tasks, of fundamental importance for the success of the project?

- Risk of assigning tasks to partners - Risks resulting from how tasks are distributed by network partners can compromise the success of the innovation process. The identification and characterization of this type of risk comprises the following aspects: Do companies have access to resources such as the knowledge, technology and capacity they need to perform the assigned tasks?
Has the workload been distributed equally by all partners?

- Risk of collaborative network management - Risks related to the authority structure and level of communication within the collaboration network. The identification and characterization of this type of risk comprises the following aspects: Can companies request help whenever it is necessary to carry out the tasks, of fundamental importance for the project success? Is the used communication approach decentralized or centralized?

- Behavioural Risks - Risks related to the types of relationships that are established between the various partners during the innovation process. The identification and characterization of this type of risk comprises the following aspects: risk of transfer of key competences to other members such as patents; assessment of the level of collaboration between companies with complementary skills; evaluation of the level of collaboration between companies with similar skills.

\section{MODEL OF INNOVATION RISK ASSESSMENT IN COLLABORATIVE ECOSYSTEMS}

The proposed model is intended to permit an assessment of the risk level associated with an innovation process and identify key constraints related with its successful implementation. In this sense, the developed model uses the concept of fuzzy logic to integrate both aspects of risk assessment, quantitative and qualitative, into a single index, as well as being a model compatible with the ambiguity and uncertainty of human assessment.

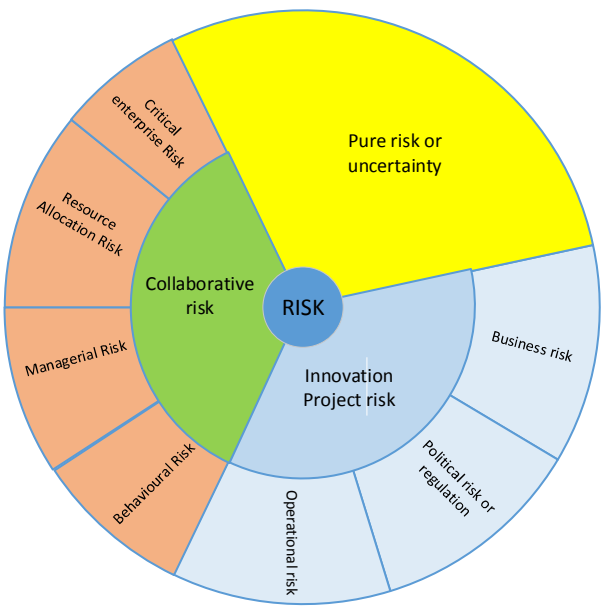

Fig. 1. Wheel of innovation risks in a collaborative ecosystem. 


\section{A. Architecture of the model}

Define abbreviations and acronyms the first time they are The proposed model, as illustrated in Fig. 2, consists of two hierarchical levels, in Level 1 the Primary Risk level $(R-)$ of a risk event is estimated as a function of probability $(P)$ and its impact $(I)$ in the process of innovation, having as reference four categories - Scope $(I S)$, Time (IT), Cost (IC) and Quality $(I Q)$. The level of Primary Risk $(R-)$, for any risk $n$ with a probability of occurrence $(P)$, for one of the four impact categories is calculated by:

$$
\begin{aligned}
& R S_{n}=P_{n} \times I S_{n} \\
& R T_{n}=P_{n} \times I T_{n} \\
& R C_{n}=P_{n} \times I C_{n} \\
& R Q_{n}=P_{n} \times I Q_{n}
\end{aligned}
$$

The Aggregate Primary Risk $\left(R_{n}\right)$ level is calculated by the following equation:

$$
R_{n}=w_{1} \times R S_{n}+w_{2} \times R T_{n}+w_{3} \times R C_{n}+w_{4} \times R Q_{n}
$$

where, $w_{n}$, represents the weighting of each variable, being $w_{1}+$ $w_{2}+w_{3}+w_{4}=1$.

Level 2 is used when assessing the capacity of the actors involved in the innovation process of predicting and responding to the risk, called Detection/Control $(D C)$. Thus, the integrated risk level $(L R-)$, for any one risk $n$, for one of the four impact categories is calculated by:

$$
\begin{aligned}
& L R S_{n}=R S_{n} \times D C_{n} \\
& L R T_{n}=R T_{n} \times D C_{n} \\
& L R C_{n}=R C_{n} \times D C_{n} \\
& L R Q_{n}=R Q_{n} \times D C_{n}
\end{aligned}
$$

The Global Aggregate Risk $\left(G R_{n}\right)$ level is calculated using the following equation:

$$
G R_{n}=w_{1} \mathrm{x} L R S_{n}+w_{2} \mathrm{x} L R T_{n}+w_{3} \mathrm{x} L R C_{n}+w_{4} \mathrm{x} L R Q_{n}
$$

In each of these levels a Fuzzy Inference System (FIS) based on a set of $I F-T H E N$ heuristic rules that is used to obtain the risk levels (by impact category). Thus, for level 1, we have:

$$
R_{x y}=P_{x} \times I_{y}
$$

Thus, inference rules are formulated as: "IF probability is $P_{x}$ $A N D$ impact is $I_{y} T H E N$ the primary risk level is $R_{x y}$ ".

Similarly, for level 2, it will be:

$$
L R_{w z}=R_{w} \times D C_{z}
$$

Therefore, the inference rules are formulated as: "IF primary risk level is $R_{w} A N D$ detection/control is $D C_{z}$ THEN integrated risk level is $L R_{w z} "$. Fig. 3 illustrates the Fuzzy Inference System for level 1 of the proposed model.

\section{B. Linguistic variables and membership functions}

The ad-hoc use of linguistic terms and corresponding membership functions is always criticized when using fuzzy logic [17]. In this phase of the model development it was decided to adopt linguistic terms and corresponding membership functions from the literature, applied in similar approaches [18, 19]. It is generally suggested that linguistic levels do not exceed nine levels, which represent the limits of human perception for discrimination [17].

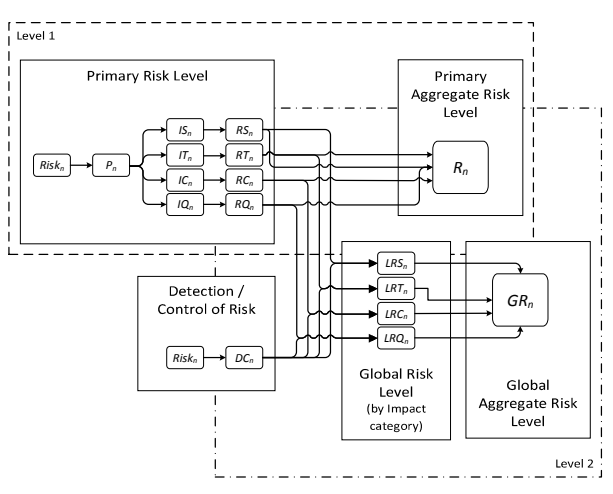

Fig. 2. Structure of the model.

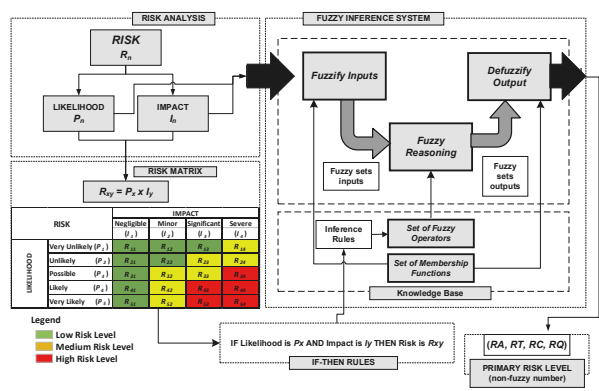

Fig. 3. Structure of the Fuzzy Inference System for level 1.

Thus, the linguistic variables and corresponding triangular membership functions were adopted for the input variables as shown in Tables I, II and III. The outputs of the proposed model are all variables whose prefixes are $R$ - or $N R$ - (primary or integrated, respectively) and Table IV illustrates the linguistic variables and corresponding membership functions adopted.

The risk assessment variables have three levels - Low, Medium and High, to contemplate the negative response strategies defined in the PMBoK - Project Management Body of Knowledge PMBoK [20]:

TABLE I. Linguistic VARiables For the Probability $(P)$ AND MEMBERSHIP FUNCTIONS

\begin{tabular}{|l|l|c|}
\hline \multicolumn{1}{|c|}{$\begin{array}{c}\text { Linguistic } \\
\text { Variables }\end{array}$} & \multicolumn{1}{|c|}{ Description } & $\begin{array}{c}\text { Membership } \\
\text { Functions }\end{array}$ \\
\hline Very Unlikely $\left(P_{l}\right)$ & Unlikely event occurrence & $(0,0,0.25)$ \\
\hline Unlikely $\left(P_{2}\right)$ & $\begin{array}{l}\text { Low probability of event } \\
\text { occurrence }\end{array}$ & $(0,0.25,0.5)$ \\
\hline Possible $\left(P_{3}\right)$ & Probable occurrence event & $(0.25,0.5,0.75)$ \\
\hline Likely $\left(P_{4}\right)$ & $\begin{array}{l}\text { Event may occur more than } \\
\text { once }\end{array}$ & $(0.5,0.75,1)$ \\
\hline Very Likely $\left(P_{5}\right)$ & Event may occur frequently & $(0.75,1,1)$ \\
\hline
\end{tabular}


2018 13th APCA International Conference on Automatic Control and Soft Computing (CONTROLO)

June 4-6, 2018, Ponta Delgada, Azores, Portugal

TABLE II. LINGUISTIC VARIABLES BY IMPACT (I) CATEGORY AND MEMBERSHIP FUNCTIONS

\begin{tabular}{|c|c|c|}
\hline $\begin{array}{l}\text { Linguistic } \\
\text { Variables }\end{array}$ & Description & $\begin{array}{l}\text { Membership } \\
\text { Functions }\end{array}$ \\
\hline \multicolumn{3}{|c|}{ Scope (IS) - deviation from the proposed objectives } \\
\hline Negligible $\left(I S_{l}\right)$ & $\begin{array}{l}\text { Responds to all objectives in } \\
\text { full or with insignificant } \\
\text { deviation in some objectives }\end{array}$ & $(0,0,3.33)$ \\
\hline Minor $\left(I S_{2}\right)$ & $\begin{array}{l}\text { One or more non-critical } \\
\text { objectives are partially met }\end{array}$ & $(0,3.33,6.66)$ \\
\hline Significant $\left(I S_{3}\right)$ & $\begin{array}{l}\text { It does not respond to some } \\
\text { non-critical objectives in its } \\
\text { entirety, or does not entirely } \\
\text { satisfy critical objectives }\end{array}$ & $(3.33,6.66,10)$ \\
\hline Severe $\left(I S_{4}\right)$ & $\begin{array}{l}\text { Risk of failure on one or more } \\
\text { critical objectives }\end{array}$ & $(6.66,10,10)$ \\
\hline \multicolumn{3}{|c|}{ Time (IT) - delay in deadlines } \\
\hline Negligible $\left(I T_{l}\right)$ & $\begin{array}{l}\text { No delays or delays without } \\
\text { relevance }\end{array}$ & $(0,0,3.33)$ \\
\hline $\operatorname{Minor}\left(I T_{2}\right)$ & Acceptable/manageable delay & $(0,3.33,6.66)$ \\
\hline Significant $\left(I T_{3}\right)$ & $\begin{array}{l}\text { It will cause unrecoverable } \\
\text { delays, requiring a change in } \\
\text { planning }\end{array}$ & $(3.33,6.66,10)$ \\
\hline Severe $\left(I T_{4}\right)$ & $\begin{array}{l}\text { Significant delays that may } \\
\text { jeopardize the success of the } \\
\text { innovation project }\end{array}$ & $(6.66,10,10)$ \\
\hline \multicolumn{3}{|c|}{ Cost (IC) - relative increase in estimated cost } \\
\hline Negligible $\left(I C_{I}\right)$ & $\begin{array}{l}\text { No deviation or slight deviation } \\
\text { within the cost estimates }\end{array}$ & $(0,0,3.33)$ \\
\hline $\operatorname{Minor}\left(I C_{2}\right)$ & $\begin{array}{l}\text { Acceptable increase, but may } \\
\text { require a revision of cost } \\
\text { estimates }\end{array}$ & $(0,3.33,6.66)$ \\
\hline Significant $\left(I C_{3}\right)$ & $\begin{array}{l}\text { Considerable deviation that may } \\
\text { have to be borne by the } \\
\text { responsible stakeholders }\end{array}$ & $(3.33,6.66,10)$ \\
\hline Severe $\left(I C_{4}\right)$ & $\begin{array}{l}\text { Large deviation that could result } \\
\text { in high costs for stakeholders, or } \\
\text { jeopardize the viability of the } \\
\text { innovation project }\end{array}$ & $(6.66,10,10)$ \\
\hline \multicolumn{3}{|c|}{ Quality (IQ) - meet stakeholders' requirements } \\
\hline Negligible $\left(I Q_{l}\right)$ & $\begin{array}{l}\text { Does not significantly } \\
\text { compromise requirements }\end{array}$ & $(0,0,3.33)$ \\
\hline Minor $\left(I Q_{2}\right)$ & $\begin{array}{l}\text { May compromise some non- } \\
\text { critical requirements }\end{array}$ & $(0,3.33,6.66)$ \\
\hline Significant $\left(I Q_{3}\right)$ & $\begin{array}{l}\text { Compromises non-critical } \\
\text { requirements and may } \\
\text { compromise critical } \\
\text { requirements }\end{array}$ & $(3.33,6.66,10)$ \\
\hline Severe $\left(I Q_{4}\right)$ & $\begin{array}{l}\text { Compromises critical } \\
\text { requirements }\end{array}$ & $(6.66,10,10)$ \\
\hline
\end{tabular}

- Accept: in this case the project members acknowledge the existence of the risk, but decide not to implement any preventive measure. This strategy is adopted when team members are unable to identify any other appropriate response strategy, or when it is not possible, or it is not feasible to eliminate risk. This strategy can be passive or active. Passive acceptance does not require any extraordinary measure in relation to the active acceptance strategy. The most widely used measure involves the implementation of contingency reserves including time, financial resources and other resources to deal with risks.
TABLE III. LINGUISTIC VARIABLES FOR THE DETECTION/CONTROL (DC) AND MEMBERSHIP FUNCTION

\begin{tabular}{|l|l|c|}
\hline \multicolumn{1}{|c|}{$\begin{array}{c}\text { Linguistic } \\
\text { Variables }\end{array}$} & \multicolumn{1}{|c|}{ Description } & $\begin{array}{c}\text { Membership } \\
\text { Functions }\end{array}$ \\
\hline Reduced $\left(D C_{l}\right)$ & $\begin{array}{l}\text { Ability to prevent and/or } \\
\text { respond to risk is questionable } \\
\text { and not guaranteed }\end{array}$ & $(0,0,50)$ \\
\hline $\begin{array}{l}\text { Reasonable } \\
\left(D C_{2}\right)\end{array}$ & $\begin{array}{l}\text { Stakeholders/organization with } \\
\text { relevant experience, however, } \\
\text { their capacity for prevention } \\
\text { and/or response is not fully } \\
\text { guaranteed }\end{array}$ & $(0,50,100)$ \\
\hline High $\left(D C_{3}\right)$ & $\begin{array}{l}\text { It is guaranteed an ability to } \\
\text { predict and respond } \\
\text { appropriately to the risk event }\end{array}$ & $(50,100,100)$ \\
\hline
\end{tabular}

TABLE IV. LINGUISTIC VARIABLES FOR RISK VARIABles $R$-(Primary) OR $L R$ - (INTEGRATED) AND MEMBERSHIP FUNCTIONS

\begin{tabular}{|l|l|c|}
\hline \multicolumn{1}{|c|}{$\begin{array}{c}\text { Linguistic } \\
\text { Variables }\end{array}$} & \multicolumn{1}{|c|}{ Description } & $\begin{array}{c}\text { Membership } \\
\text { Functions }\end{array}$ \\
\hline Low $(L)$ & $\begin{array}{l}\text { Accept - does not compromise the } \\
\text { viability of the project, however } \\
\text { its "existence" should not be } \\
\text { neglected }\end{array}$ & $(0,0,5)$ \\
\hline Medium $(M)$ & $\begin{array}{l}\text { Mitigate - Can compromise } \\
\text { project viability; management } \\
\text { should monitor the cause of the } \\
\text { event }\end{array}$ & $(0,5,10)$ \\
\hline High $(H)$ & $\begin{array}{l}\text { Prevent - The viability of the } \\
\text { project is compromised; } \\
\text { management should give high } \\
\text { priority to its resolution }\end{array}$ & $(5,10,10)$ \\
\hline
\end{tabular}

- Mitigate: in this case project members must implement the necessary measures to reduce the probability of occurrence or the impact of a risk. This implies a reduction of the likelihood, and/or impact of an adverse risk, to limits considered acceptable. Taking early actions to reduce the likelihood and / or impact of a risk is often more effective than attempting to repair the damage after the risk has occurred. Adopting simpler processes, conducting more trials or choosing more reliable suppliers and partners are examples of mitigation actions. When it is not possible to reduce the probability of occurrence, a mitigation strategy can be to seek to reduce the impact of the risk, for example through the implementation of redundant processes, thus achieving a reduction of its severity.

- Prevent: in this case project members must implement the necessary measures that lead to the elimination of the threat or protect the project from the impacts of the risk. Examples of some measures are: lengthening the duration of the project, reducing scope, changing objectives that are endangered, improving communication or acquiring specialized skills, among others. However, the most radical prevention strategy is to close the project.

\section{Model Implementation Process}

The proposed model was developed in MATLAB ${ }^{\circledR}$ software, using Fuzzy Logic Toolbox ${ }^{\mathrm{TM}}$ (called Fuzzy Logic Designer in version R2016a). Thus, in the Fuzzy Logic Designer the two 
levels of the proposed model were implemented, using in this exploratory phase the approach proposed by Mamdani for the fuzzy inference mechanism. The choice of the approach proposed by Mamdani is due to the fact that it is intuitive and better adapted to inputs from human reasoning and to have a wide acceptance [19]. As shown in Fig. 4, level 1 of the model has as inputs the Probability $(P)$ and the Impact $(I)$; and outputs the Primary Risk Level by category $(R)$. Level 2 of the model has as inputs the Primary Risk Level by category $(R)$ and the Risk Detection/Control $(D C)$ and outputs the Integrated Risk Level by category $(L R)$.

Among the several defuzzification methods presented in the literature, the centroid method was used as the defuzzification approach for the inference system proposed in this paper, as it is the most commonly used, for applications of the genus. After constructing the entire model, Figs. 5 and 6 illustrate the risk surfaces that can be obtained for the two levels of the developed model.

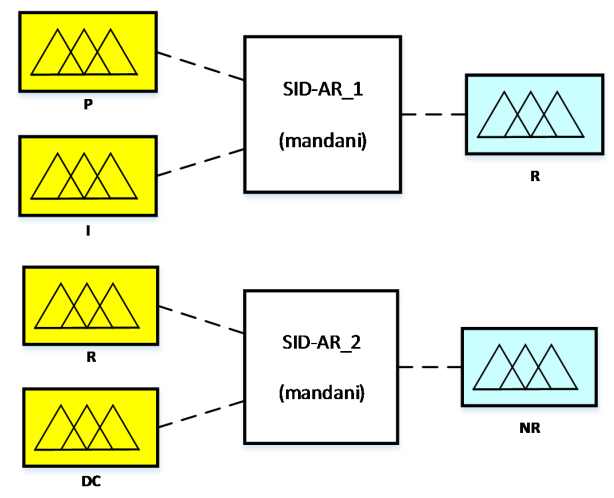

Fig. 4. Fuzzy Inference System for level 1 and 2.

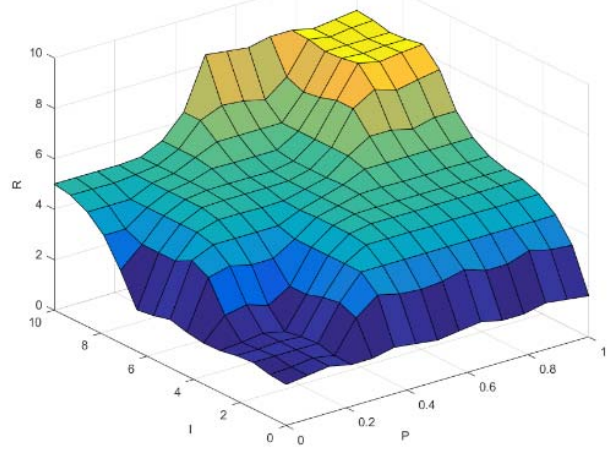

Fig. 5. Surface of the Fuzzy Inference System for level 1.

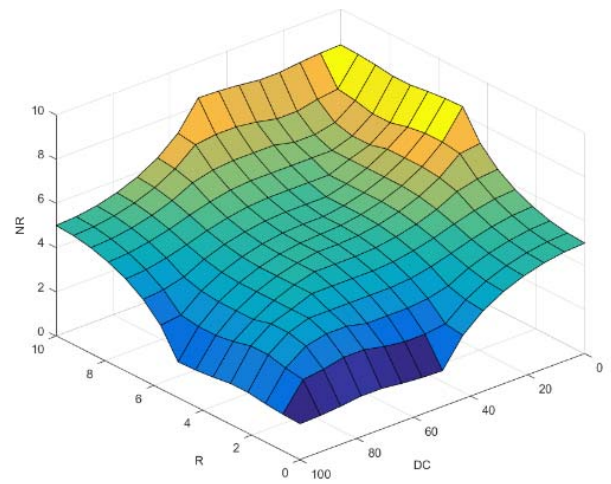

Fig. 6. Surface of the Fuzzy Inference System for level 2.

\section{Case Study}

The developed model was applied in an innovation network project concerned with the design phase of a piping system for the transportation of fluids. It intends to evaluate the risks inherent to the projects of these infrastructures for the process industry, focusing on the risks associated with the variables involved and the corresponding decisions taken in the design phase. Risks in piping design may have multiple sources that may have several origins such as technological, economic, organizational, human, among others. These may be associated with for example: limitations in the characteristics of materials or their wrong selection; limitations of economic resources; lack of experience of those involved; limitations in the organizations management; tight deadlines; design errors; limitations of applied tools; etc. Considering the case study considered to assess the robustness of the authors' proposed approach, Table $\mathrm{V}$ shows the four identified risks associated with the piping design.

For the application of the model to the four risks considered, a group of experts evaluated the six parameters that constitute the inputs of the model: $P_{n}, I S_{n}, I T_{n}, I C_{n}, I Q_{n}, D C_{n}$ for each of the risks. Table VI illustrates the classification assigned to the "Over-engineering" risk. After applying the model developed, Table VII illustrates the results obtained for the four risks under analysis.

Based on the results obtained, in overall terms of the four risks considered, Risk 1 - Over-engineering - is the one with the highest Integrated Risk Level (LR). In a more detailed risk analysis, we can verify that the occurrence of this risk produces a greater negative impact at the level of the time (RT), that is, the execution time of the innovation project will tend to be higher than initially defined if no mitigation strategies or of prevention of this risk, are defined.

However, as the value of $(L R T)$ is lower than that of $(R T)$ we can see that the network members that participate in this innovation project already have implemented detection / control mechanisms that allow a reduction of probability of risk and / or impact, achieving thereby reducing its severity. 
TABLE V. IDENTIFIED RISKS IN PIPING DESIGN

\begin{tabular}{|c|l|}
\hline Risk & \multicolumn{1}{c|}{ Description } \\
\hline Risk 1 & $\begin{array}{l}\text { Over-engineering - The risk of over-enginnering events occurs } \\
\text { when a solution developed for the project is more complex or } \\
\text { robust than is necessary to meet expected requirements and is } \\
\text { considered wasteful from a value-added point of view. It } \\
\text { occurs for example with the application of exaggerated } \\
\text { security coefficients, oversizing, inefficient application of } \\
\text { materials, etc. }\end{array}$ \\
\hline Risk 2 & $\begin{array}{l}\text { Application of materials not readily available on site - The risk } \\
\text { of unforeseen difficulties in making the various materials and } \\
\text { components available at the site of implementation of the } \\
\text { infrastructures. It occurs if during the design phase, and in the } \\
\text { selection of the materials, all the variables of the procurement } \\
\text { and delivery of materials are not considered and weighted. }\end{array}$ \\
\hline Risk 3 & $\begin{array}{l}\text { Errors in information upstream (project inputs) - The risk of } \\
\text { project inputs are inconsistent or wrong potentially originates } \\
\text { design errors events. }\end{array}$ \\
\hline Risk 4 & $\begin{array}{l}\text { Low Flow Efficiency - A pipeline under design has the } \\
\text { ultimate goal of allowing the displacement of a fluid inside it, } \\
\text { and the thermodynamic properties to be verified in the flow } \\
\text { during the installation are an input of the project. There is a } \\
\text { risk that after the design of the lines, flow conditions that do } \\
\text { not coincide with the expected ones will be foreseen, with } \\
\text { low flow efficiency. }\end{array}$ \\
\hline
\end{tabular}

TABLE VI. RISK "OVER-ENGINEERING" - RISKS IDENTIFIED IN PIPING DESIGN

\begin{tabular}{|c|c|c|c|c|c|}
\hline$P$ & $I S$ & $I T$ & IC & $I Q$ & $D C$ \\
\hline$P_{I}$ & $I S_{l}$ & $I T_{l}$ & $I C_{l}$ & $I Q_{l}$ & $D C_{I}$ \\
\hline$P_{2}$ & $I S_{2}$ & $I T_{2}$ & $I C_{2}$ & $I Q_{2}$ & $D C_{2}$ \\
\hline$P_{3}$ & $I S_{3}$ & $I T_{3}$ & $I C_{3}$ & $I Q_{3}$ & $D C_{3}$ \\
\hline$P_{4}$ & $I S_{4}$ & $I T_{4}$ & $I C_{4}$ & $I Q_{4}$ & \\
\hline$P_{5}$ & & & & & \\
\hline
\end{tabular}

TABLE VII. RESUlts of PIPING DeSIGN Risk ASSESSMENT

\begin{tabular}{|l|l|l|l|l|}
\hline OUTPUT & \multicolumn{1}{|c|}{ RISK 1 } & RISK 2 & RISK 3 & RISK 4 \\
\hline$R S$ & 5 & 5 & 5 & 5 \\
\hline$R T$ & 8,22 & 6,14 & 5 & 1,63 \\
\hline$R C$ & 5 & 5 & 3,86 & 1,63 \\
\hline$R Q$ & 3,86 & 5 & 5 & 5 \\
\hline$L R S$ & 6,14 & 3,86 & 5 & 3,86 \\
\hline$L R T$ & 6,11 & 4,06 & 5 & 3,84 \\
\hline$L R C$ & 6,14 & 3,86 & 4,87 & 3,84 \\
\hline$L R Q$ & 5,94 & 3,86 & 5 & 3,86 \\
\hline$N R\left(\sum\right)$ & $\mathbf{6 , 0 8}$ & $\mathbf{3 , 9 1}$ & $\mathbf{4 , 9 7}$ & $\mathbf{3 , 8 5}$ \\
\hline
\end{tabular}

\section{CONCLUSIONS}

All organizations are aiming for success. Today's success is measured by the growth in profits, the leadership of the market share supported by customer satisfaction and the ability to innovate.

In this context, the role of innovation risk assessment was discussed, and a model was proposed to measure the level of risk associated with the development of an innovation project in a collaborative context.
Furthermore, in a context characterized by uncertainty and ambiguity, the risk assessment is inevitably dependent on human perception. As a result, the assessment the risk level based on fuzzy inference systems becomes more rigorous. Since based on this approach, it is possible to mitigate the analysis subjectivity.

On the other hand, while the classic models of risk assessment are based only on the perception of risk based on the probability of occurrence and its impacts, the recommended model also covers the ability of the stakeholders in the innovation project to anticipate and respond appropriately to risk. This property allows to assess the level of risk that two distinct organizations will have on the risk level of the same risk event in an innovation project. However, more tests are needed to assess and validate the robustness of proposed model and its capability to cope with a variety of innovation project in different knowledge domains.

\section{ACKNOWLEDGMENTS}

This work was partially supported by the Polytechnic Institute of Lisbon through the Projects for Research, Development, Innovation and Artistic Creation (RDI\&AC), within the framework of the project ARPIPME - Evaluation of the risk of innovation processes in small and medium enterprises. And, it was also partially supported by FCT, through IDMEC, under LAETA, project UID/EMS/50022/2013.

\section{REFERENCES}

[1] J. Storey and S. Salaman, Managers of Innovation. Blackwell Publishing, UK, 2005.

[2] A. Afuah, Innovation Management - Strategies, Implementation, and Profits. Oxford University Press, 2003.

[3] J. G. Vargas-Hernández, M. R. Noruzi and N. Sariolghalam, "Risk or innovation, which one is far more preferable in innovation projects?", in International Journal of Marketing Studies, vol. 2, n 1, 2010, pp. 233244.

[4] R. Taplin, Risk Management and Innovation in Japan, Britain and the United States. Routledge, UK, 2005

[5] ISO 31000 Risk management - Principles and guidelines, 2009.

[6] C. Chapman, C. and S. Ward, Project Risk Management - Process, Techniques and Insights. Wiley, UK, 1997.

[7] B. S. Tether, "Who co-operates for innovation, and why: an empirical analysis", in Research Policy, vol. 31, n 6, 2002, pp. 947-967.

[8] A. Abreu, and L. M. Camarinha-Matos, "An Approach to Measure Social Capital in Collaborative Networks", in Working Conference on Virtual Enterprises, Springer Berlin Heidelberg, 2011, pp. 29-40.

[9] A. Tenera, A. and A. Abreu, "A TOC perspective to improve the management of collaborative networks", in Working Conference on Virtual Enterprises, Springer US, 2008, pp. 167-176.

[10] L. M. Camarinha-Matos and A. Abreu, "A contribution to understand collaboration benefits", in Emerging Solutions for Future Manufacturing Systems, L.M. Camarinha-Matos, Editor. Springer, 2004.

[11] M. J. Nieto and L. Santamaría, "The importance of diverse collaborative networks for the novelty of product innovation", in Technovation, vol. 27, $\mathrm{n}^{\circ} 6,2007$, pp. 367-377.

[12] G. Monahan, Enterprise Risk Management: A Methodology for Achieving Strategic Objectives. John Wiley \& Sons, 2008.

[13] R. J. Chapman, Simple Tools and Techniques for Enterprise Risk Management, 2th Edition. John Wiley \& Sons, 2011.

[14] A. Abreu and J. M. F. Calado, "A Risk Model to Support the Governance of Collaborative Ecosystems", Proc. of 20th World Congress of the International Federation of Automatic Control, Toulouse, França, vol. 50, $\mathrm{n}^{\circ}$ 1, 9-14 July 2017, pp. 10544-10549. 